\title{
PONTO DE EFEITO SALINO NULO: DETERMINAÇÃO ANALÍTICO-COMPUTACIONAL A PARTIR DE DADOS DE TITULAÇÃO POTENCIOMÉTRICA(1)
}

\author{
M. E. ALVES ${ }^{(2)}$, C. R. MACEDONIO ${ }^{(3)} \&$ A. LAVORENTI(4)
}

\begin{abstract}
RESUMO
O ponto de efeito salino nulo (PESN) de amostras de solo é normalmente determi nado por método gráfico e corresponde ao valor de $\mathrm{pH}$ referente ao ponto de interseção de curvas de titulação potenciométrica. E mbora a elaboração dos gráficos em planilhas eletrônicas diminua a subjetividade existente no traçado manual, um tempo considerável é necessário quando a determi nação do PESN envolve grande número de amostras. Este trabal ho objetivou o desenvolvimento de um programa computacional para a determinação analítica do PESN de amostras de solo, com vistas em eliminar a subjetividade do método gráfico, proporcionar rapidez às determinações e permitir o conhecimento do grau de precisão dos valores calculados. Com o procedimento de cálculo desenvolvido, determinaram-se os valores de PESN a partir de resultados experimentais de titulação potenciométrica obtidos por outros autores. A comparação dos valores calculados pelo programa com os apresentados nos trabalhos consultados, os quais foram obtidos pelos autores por meio do método gráfico convencional, demonstrou ser o método analítico-computacional proposto bastante adequado para a determi nação rápi da e não-subjetiva do PESN de amostras de solo.
\end{abstract}

Termos de indexação: PCZ, software, atributo eletroquímico.

\footnotetext{
(1) Parte da Tese de Doutorado do primeiro autor, apresentada ao Programa de Pós-Graduação em Solos e Nutrição de Plantas da Escola Superior de Agricultura "Luiz de Queiroz" - ESALQ/USP. Trabalho apresentado no XXVIII Congresso Brasileiro de Ciência do Solo, Londrina (PR), 1 a 6 de julho de 2001. Recebido para publicação em abril de 2001 e aprovado em janeiro de 2002.

(2) Engenheiro-Agronômo. Rua doTrabal ho 196, Vila Independência, CEP 13418-220 Piracicaba (SP). E-mail: mealves@i best.com.br

(3) Técnico em Informática do Departamento de Genética, ESALQ/USP. E-mail: crmacedo@esalq.usp.br

(4) Professor do Departamento de Ciências Exatas, ESALQ/USP. E-mail: alavoren@esalq.usp.br
} 


\title{
SUMMARY: PZSE: ANALYTICAL-COMPUTATIONAL APPROACH TO ITS DETERMINATION FROM POTENTIOMETRIC TITRATION DATA
}

\begin{abstract}
The point of zero salt effect (PZSE) of soil samples is usually determined by a graphic method wherethePZSE corresponds to thepH valueobserved at thecrossing point of drafted potentiometric titration curves. Although the use of graphic software decreases thepersonal bias that normally occurs when thetitration curves aredrafted by hand, this determination method can be timeconsuming when thereis a great number of soil samples. The present work aimed to devel op a software to permit rapid and non-subjective determination of the PZSE of soil samples as well as to evaluatetheprecision of calculated values. By a comparison of the program calculated values with those presented in theconsulted studies, obtained by authors using theconventional graphic method, theproposed computational analytic method proved to be adequatefor the purposes above mentioned.
\end{abstract}

Index terms: PZC, software, electrochemical attribute.

\section{INTRODUÇÃO}

O ponto de efeito salino nulo (PESN) corresponde ao valor de $\mathrm{pH}$ no qual a concentração salina da solução em contato com a fase sólida não exerce influência sobre a magnitude das cargas elétricas de caráter variável quese manifestam na superfície das partículas coloidais existentes no solo (Sposito, 1989). A determinação do valor desse atributo é de grande importância em estudos físico-químicos dos solos com cargas variáveis, visto que alguns fenômenos el etroquími cos que ocorrem na interface sólido-líquido são influenciados pela distribuição superficial de cargas elétricas, a qual varia de acordo com a diferença existente entre os valores de $\mathrm{pH}$ e de PESN. Além disso, fenômenos el etroquímicos, como a adsorção específica de cátions e ânions, podem promover modificações na distribuição superficial de cargas, as quais se podem refletir em mudanças no val or do PESN.

O PESN é normalmente determinado por meio de gráficos construídos a partir de resultados experimentais de titulação potenciométrica, sendo igual ao valor de $\mathrm{pH}$ correspondente ao ponto de interseção de curvas estabelecidas para diferentes concentrações salinas. E ssas curvas relacionam as quantidades de íons $\mathrm{H}^{+}$e $\mathrm{OH}^{-}$adsorvidos por amostras de solo aos valores de $\mathrm{pH}$ atingidos pelas suspensões na condição de equilíbrio (Raij \& Peech, 1972).

Teoricamente, todas as curvas de titulação potenciométrica deveriam cruzar-se em um mesmo ponto; contudo, em geral isso não ocorre. Em alguns casos, pode-se observar mais de um ponto de interseção entre as curvas traçadas, especialmente quando a determinação do PESN é efetuada em amostras provenientes de solos menos intemperizados.
O uso de planil has el etrônicas na elaboração das curvas detitulação potenciométrica ea subseqüente determinação manual do ponto de cruzamento dessas curvas reduzem a subjetividade existentena determinação convencional do valor do PESN. Contudo, mesmo com esse procedimento, um tempo considerável é necessário para definir o PESN nos casos em quegrandenúmero deamostraséanalisado.

Nesse contexto, este trabalho objetivou o desenvolvimento de um método analíticocomputacional, com vistas em possibilitar a determinação rápida e não-subjetiva do valor do PESN de amostras de solo e permitir, ao mesmo tempo, o conhecimento do grau de precisão dos valores calculados.

\section{MATERIAL E MÉTODOS}

\section{Estabelecimento da relação funcional entre dados de titulação potenciométrica}

A primeira etapa do desenvol vimento do método de determinação analítico-computacional do PESN consistiu na identificação de uma relação funcional entre as variáveis medidas na etapa de titulação potenciométrica, ou seja, entre os val ores de $\mathrm{pH}$ das suspensões e as quantidades adsorvidas $\mathrm{de}^{+} \mathrm{eOH}^{-}$ pelas amostras de solo nas diferentes séries eletrolíticas. A função ideal deveria ser aplicável tanto a vários tipos de solos, os quais deveriam apresentar ampla variação quanto aos atributos que exercem influência sobre o PESN, quanto a todas as séries el etrolíticas comumente utilizadas no método potenciométrico. Além desses aspectos, seria desejável que o modelo em questão não oferecesse grande dificuldade computacional para seu ajuste matemático e para o cál culo de suas raízes. 
Visando definir a relação funcional supracitada, amostras de camadas subsuperficiais de quinze sol os representativos do estado de São Paulo foram coletadas, secas ao ar e passadas em peneira de $2 \mathrm{~mm}$ de malha. Em seguida, essas amostras foram caracterizadas e utilizadas para a obtenção dos dados necessários à determinação do PESN.

As determinações de pH e dos teores de óxidos dos ataques sulfúrico e alcalino foram realizadas segundo EMBRAPA (1997). A semiquantificação dos teores de caulinita e gibbsita na fração argila desferrificada foi efetuada por meio de análise térmica diferencial, com posterior correção dos teores para a fraçãoargila. Os teores dehematita e goethita foram estimados a partir dos teores de Fe extraídos na fração argila com ditionito-citrato e oxal ato ácido de amônio (Buurman et al., 1996) e dos valores da relação $\mathrm{Hm} /(\mathrm{Hm}+\mathrm{Gt})$ e da substituição em Al na estrutura desses óxidos, os quais foram cal culados a partir de dados obtidos por meio de difratometria de raios X (Resendeet al., 1987; Netto, 1996) (Quadro 1).

Os dados de titulação potenciométrica utilizados no procedimento de cálculo foram obtidos em triplicata, empregando-se o método proposto por Raij $\&$ Peech (1972), com modificações adotadas por Costa et al. (1984). Foram utilizadas três séries el etrolíticas, constituídas por soluções de $\mathrm{NaCl}$, nas concentrações de 0,$1 ; 0,01$ e 0,001 $\mathrm{mol} \mathrm{L}^{-1}$, e seis recipientes por série.

U ma vez obtidos, os dados de titulação potenciométrica foram utilizados para o ajuste de várias equações por meio do software Table Curve ${ }^{\circledR}$. O ajustamento das equações foi efetuado separadamente para cada série eletrolítica, considerando o valor de $\mathrm{pH}$ das suspensões como variável dependente das quantidades $\mathrm{deH}^{+} \mathrm{eOH}^{-}$adsorvidos pelas subamostras de solo. Esse procedimento permitiu verificar que, dentreas várias equações que se ajustaram ao fenômeno, o model o polinomial de quarto grau foi o que melhor se adequou aos requisitos estabelecidos para a escol ha da relação funcional de interesse.

Verificou-se quenãohouve influência significativa da heterogenei dade das amostras utilizadas sobre a adequação do model o polinomial de quarto grau na estimativa de val ores de $\mathrm{pH}$ a partir das quantidades adsorvidas de $\mathrm{H}^{+}$e $\mathrm{OH}^{-}$pelas amostras de solo (Figura 1).A excelentecorrespondên-cia obtida entre os val ores de $\mathrm{pH}$ medidos e os estimados pel o model o polinomial de quarto grau foi observada para todas as séries el etrol íticas utilizadas, mesmo considerando a variabilidade apresentada pel o conjunto de solos no que se refere aos atributos relacionados, direta ou inversamente, com o PESN, tais como: o grau de intemperismo, avaliado pelo índice Ki $\left(r=-0,80^{* *}\right)$, os teores de caulinita $\left(r=-0,68^{* *}\right)$ ea soma dos teores de gibbsita, hematita e goethita $\left(r=0,80^{* *}\right)$.

\section{Desenvolvimento dos procedimentos de cálculo e programação}

Considerando a equação polinomial de quarto grau para o ajustamento das curvas de titulação potenciométrica, foi desenvolvido um procedimento de cálculo para determinar o valor do PESN. Um programa computacional foi elaborado, utilizando o sistema de desenvol vimento de aplicativos Borland Del phi Standard 3.0 ${ }^{\circledR}$ para a realização dos cálculos e apresentação dos resultados.

\section{Quadro 1. I dentificação, localização e alguns atributos dos solos estudados}

\begin{tabular}{|c|c|c|c|c|c|c|c|c|c|c|}
\hline Solo & Classe & Localização & $\Delta \mathbf{p} \mathbf{H}^{(1)}$ & PESN & $\mathbf{K i} \mathbf{i}^{(2)}$ & $\mathbf{C t}^{(3)^{*}}$ & $\mathbf{G b}^{(\mathbf{4}) *}$ & $\mathrm{Hm}^{(5) *}$ & $\mathbf{G t}^{(\mathbf{6})^{*}}$ & $\mathbf{O x} \mathbf{x}^{(7)^{*}}$ \\
\hline & & & & & & & & $-\mathrm{g} \mathrm{kg}^{-1}$ & & 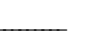 \\
\hline 1 & Latossolo Vermel ho acriférrico & Ribeirão Preto & 0,11 & 5,57 & 0,72 & 234 & 459 & 224 & 33 & 715 \\
\hline 2 & Latossolo Vermel ho eutroférrico & I racemápolis & $-0,77$ & 5,77 & 1,14 & 405 & 245 & 205 & 37 & 487 \\
\hline 3 & Latossolo Vermel ho distroférrico & Luís Antônio & $-0,08$ & 4,47 & 0,97 & 408 & 337 & 211 & 9 & 557 \\
\hline 4 & Latossolo Vermel ho acriférrico & Luís Antônio & 0,36 & 6,07 & 0,49 & 150 & 543 & 224 & 40 & 807 \\
\hline 5 & Latossolo Amarelo ácrico & Guaíra & 0,87 & 6,96 & 0,85 & 297 & 357 & 0 & 207 & 564 \\
\hline 6 & Latossolo Vermelho distrófico & Piracicaba & $-0,82$ & 4,10 & 1,44 & 522 & 119 & 23 & 110 & 253 \\
\hline 7 & Latossolo Vermelho-Amarelo distrófico & Piracicaba & $-0,94$ & 3,46 & 1,65 & 632 & 10 & 21 & 85 & 115 \\
\hline 8 & L atossolo Vermel ho-Amarelo distrófico & São Carlos & $-0,42$ & 4,50 & 0,69 & 256 & 553 & 2 & 160 & 714 \\
\hline 9 & Nitossolo Vermel ho eutroférrico & Piracicaba & $-0,63$ & 4,80 & 1,56 & 534 & 23 & 128 & 84 & 235 \\
\hline 10 & Argissolo Vermel ho-Amarelo distrófico & Pindorama & $-1,12$ & 2,89 & 1,75 & 601 & 2 & 3 & 85 & 90 \\
\hline 11 & Argissolo Vermel ho-Amarelo distrófico & Vera Cruz & $-0,76$ & 3,47 & 1,81 & 773 & 0 & 14 & 56 & 70 \\
\hline 12 & Argissol o Vermel ho distrófico & Rio Claro & $-0,81$ & 4,03 & 1,63 & 530 & 0 & 23 & 125 & 148 \\
\hline 13 & Argissolo Vermel ho distrófico & Piracicaba & $-1,12$ & 3,58 & 1,66 & 513 & 9 & 26 & 89 & 123 \\
\hline 14 & Argissolo Vermel ho-Amarel o eutrófico & São Pedro & $-1,32$ & 3,40 & 2,13 & 282 & 2 & 11 & 52 & 65 \\
\hline 15 & N eossolo Quartzarênico órtico & São Pedro & $-0,47$ & 3,49 & 1,66 & 683 & 16 & 6 & 66 & 87 \\
\hline
\end{tabular}

(1) $\Delta \mathrm{pH}=\mathrm{pH} \mathrm{KCl} 1 \mathrm{~mol} \mathrm{~L}^{-1}-\mathrm{pH} \mathrm{H}_{2} \mathrm{O} .{ }^{(2)} \mathrm{Ki}=1,7 \times\left(\mathrm{SiO}_{2}\right) /\left(\mathrm{Al}_{2} \mathrm{O}_{3}\right) \cdot{ }^{(3)} \mathrm{Ct}=$ caulinita. ${ }^{(4)} \mathrm{Gb}=$ gibbsita. ${ }^{(5)} \mathrm{Hm}=$ hematita. ${ }^{(6)} \mathrm{Gt}=$ goethita.

(7) $\mathrm{Ox}=\mathrm{Gb}+\mathrm{Hm}+\mathrm{Gt}$. * Teor na fração argila. 


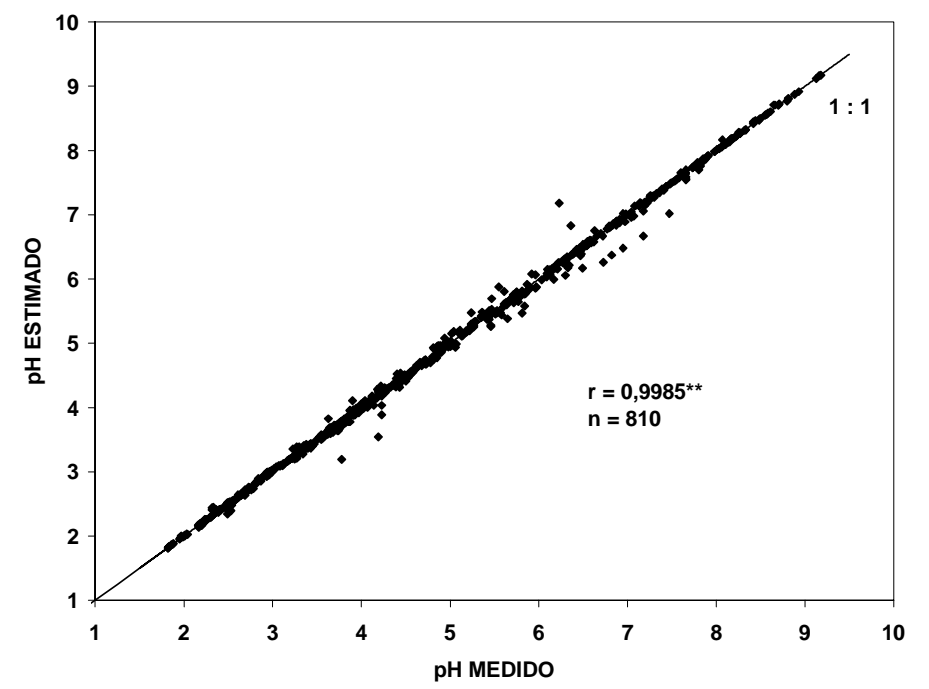

Figura 1. Relação entre os valores medidos de pH e os esti mados pelo modelo polinomial de quarto grau.

A partir das concentrações molares de $\mathrm{H}^{+}$e de $\mathrm{OH}^{-}$nas soluções salinas, do vol ume dessas soluções nos recipientes (ou dos volumes de ácido e de base adicionados às soluções salinas, conforme método utilizado por Costa et al., 1984) e da massa de solo utilizada para as determi nações, o programa realiza o cál culo das quantidades de íons $\mathrm{H}^{+}$e $\mathrm{OH}^{-}$ adsorvidos pelas amostras, as quais são expressas $\mathrm{em} \mathrm{mmol}{ }_{\mathrm{c}} \mathrm{kg}^{-1}$ de solo. $\mathrm{E} \mathrm{m}$ seguida, utilizando esses val ores cal culados e os valores de $\mathrm{pH}$ atingidos pelas suspensões, o sistema efetua o ajustamento da equação polinomial do quarto grau para cada série eletrolítica, segundo o método dos quadrados mínimos. Para tanto, o programa gera um sistema de equações normais, que, no caso de um pol inômio de quarto grau, consiste em um sistema linear constituído por cinco equações e cinco incógnitas, e o soluciona com o emprego do método do escal onamento.

Ao considerar a determinação gráfica do PESN, verifica-se que o ponto de cruzamento entre duas curvas de titulação potenciométrica corresponde a um valor comum de $\mathrm{pH}$ para ambas as séries eletrolíticas envolvidas. Desse modo, considerando que a determinação do PESN envolve normalmente três séries eletrolíticas, podem-se determinar separadamente três valores de $\mathrm{pH}$ referentes aos pontos de cruzamento das curvas de titulação potenciométrica tomadas duas a duas. Teoricamente, esses três val ores deveriam ser iguais, contudo, nem sempre isso se verifica.

Com a adoção da abordagem analítica para a descrição das curvas de titulação potenciométrica pelo polinômio de quarto grau, verifica-se que cada um dos três pontos de cruzamento supracitados pode ser cal culado por meio da subtração dos respectivos coeficientes das equações ajustadas, tomadas aos pares, determinando a raiz da equação resultante e substituindo o valor encontrado em qualquer dos polinômios do par considerado.
O programa efetua as subtrações dos coeficientes das equações ajustadas gerando três novas equações, cujas raízes são calculadas iterativamente com o emprego do método de Newton-Raphson. Em seguida, esses val ores são substituídos em uma das equações polinomiais que geraram a equação solucionada, resultando no cálculo dos valores parciais do PESN. O valor do PESN fornecido pelo programa corresponde à média aritmética dos três valores parciais encontrados, à qual são associados os valores do desvio-padrão e do coeficiente de variação.

A equação polinomial de quarto grau, embora proporcione excel ente concordância entre os val ores de $\mathrm{pH}$ medidos e estimados, apresenta a desvantagem de poder admitir até quatro valores distintos para as suas raízes. Esse fato poderia resultar na obtenção de valores incorretos para o PESN, visto que, dependendo da proximidade dos valores das diferentes raízes e do valor inicial utilizado nas iterações, poderá haver convergência para val ores diferentes daquel e que corresponde ao ponto de interseção de interesse.

Para contornar esse problema, o sistema define a amplitude mínima comum de quantidades adsorvidas de $\mathrm{H}^{+}$e $\mathrm{OH}^{-}$para as três concentrações salinas e, em seguida, realiza uma série de substituições do início ao fim do intervalo gerado, com incrementos de $0,5 \mathrm{mmol}_{\mathrm{C}} \mathrm{kg}^{-1}$ de $\mathrm{H}^{+} / \mathrm{OH}^{-}$, em cada equação gerada pelas subtrações de coeficientes.

Desse modo, é possível identificar as quantidades adsorvidas de $\mathrm{H}^{+}$ou $\mathrm{OH}^{-}$que geram os quatro menores val ores absolutos para as diferenças entre valores de $\mathrm{pH}$ nas duas séries eletrolíticas consi deradas. Os val ores encontrados são utilizados para o início das iterações do método de NewtonRaphson, resultando no cálculo de quatro raízes, as quais poderão ser iguais ou diferentes. A substituição 
de cada um desses valores em uma das duas equações polinomiais, cujos coeficientes foram subtraídos, possibilita o cálculo de quatro valores parciais de PESN para cada concentração salina. Esses quatro valores são combinados levando em consideração as três séries el etrolíticas e sessenta e quatro valores médios para o PESN são calculados. Das médias calculadas, o valor do PESN corresponderá àquela associada ao menor coeficiente de variação. Esse procedimento, além de evitar a determinação de valores errôneos de PESN pelas razões mencionadas, permite, em alguns casos, contornar o problema da existência de mais de um ponto de cruzamento entre as curvas de titulação potenciométrica, visto que um valor mínimo para o coeficiente de variação como critério de sel eção da média implica a máxima proximidade dos três valores parciais de PESN.

Após o estabelecimento da rotina de cálculo, valores de PESN foram calculados com o uso do programa a partir de dados experimentais de titulação potenciométrica extraídos dos trabal hos de Alleoni (1992) e Dynia (1993). Esses valores foram então comparados aos apresentados nos trabal hos consultados, os quais foram determinados pelos referidos autores com o emprego do método gráfico manual. Adicionalmente, efetuou-sea determinação gráfica dos valores de PESN a partir dos mesmos dados de titulação potenciométrica supracitados, utilizando-se o programa Microsoft Excel $2000^{\circledR}$. Os valores de PESN obtidos por esse procedimento foram também comparados aos obtidos pel o método analítico-computacional.

\section{RESULTADOS E DISCUSSÃO}

Os valores de PESN calculados pelo programa a partir dos dados de titulação potenciométrica apresentados nos trabalhos de Alleoni (1992) (amostras 1 a 11) eDynia (1993) (amostras 12 a 26), os valores obtidos pelos referidos autores com o método gráfico manual e os determinados graficamente com o uso de planilha el etrônica são apresentados no quadro 2. A maior diferença

Quadro 2. Valores do PESN de amostras de solo obtidos a partir do método gráfico e cal culados pelo programa, precisão dos valores calculados e valores das diferenças observadas entre os dois métodos de determinação

\begin{tabular}{|c|c|c|c|c|c|c|}
\hline Amostra & PESN gráficol ${ }^{(1)}$ & PESN gráfico 2 (2) & PESN calculado(3) & C.V. (\%)(4) & Desviol (5) & Desvio2 (6) \\
\hline 1 & 3,70 & 3,61 & 3,50 & 3,88 & 0,20 & 0,11 \\
\hline 2 & 3,50 & 3,44 & 3,30 & 3,60 & 0,20 & 0,14 \\
\hline 3 & 3,50 & 3,39 & 3,30 & 1,37 & 0,20 & 0,09 \\
\hline 4 & 3,50 & 3,45 & 3,40 & 2,36 & 0,10 & 0,05 \\
\hline 5 & 3,50 & 3,45 & 3,40 & 0,77 & 0,10 & 0,05 \\
\hline 6 & 3,80 & 3,78 & 3,60 & 2,48 & 0,20 & 0,18 \\
\hline 7 & 3,80 & 3,70 & 3,60 & 1,82 & 0,14 & 0,10 \\
\hline 8 & 3,70 & 3,70 & 3,50 & 3,54 & 0,29 & 0,20 \\
\hline 9 & 3,80 & 3,86 & 3,70 & 4,72 & 0,10 & 0,16 \\
\hline 10 & 3,80 & 3,86 & 3,70 & 4,78 & 0,10 & 0,16 \\
\hline 11 & 4,60 & 4,35 & 4,30 & 7,01 & 0,30 & 0,05 \\
\hline 12 & 4,50 & 4,42 & 4,20 & 7,01 & 0,30 & 0,22 \\
\hline 13 & 4,40 & 4,21 & 4,10 & 6,20 & 0,30 & 0,11 \\
\hline 14 & 4,30 & 4,31 & 4,10 & 6,51 & 0,20 & 0,21 \\
\hline 15 & 4,40 & 4,48 & 4,30 & 8,53 & 0,10 & 0,18 \\
\hline 16 & 3,65 & 3,62 & 3,62 & 3,64 & 0,03 & 0,00 \\
\hline 17 & 3,60 & 3,65 & 3,62 & 2,87 & $-0,02$ & 0,03 \\
\hline 18 & 3,65 & 3,65 & 3,70 & 2,63 & $-0,05$ & $-0,05$ \\
\hline 19 & 6,15 & 5,98 & 5,95 & 8,13 & 0,20 & 0,03 \\
\hline 20 & 3,60 & 3,55 & 3,60 & 1,28 & 0,00 & $-0,05$ \\
\hline 21 & 5,65 & 5,52 & 5,50 & 2,64 & 0,10 & $-0,03$ \\
\hline 22 & 3,40 & 3,37 & 3,38 & 2,69 & 0,02 & $-0,03$ \\
\hline 23 & 5,80 & 5,68 & 5,66 & 4,94 & 0,14 & 0,02 \\
\hline 24 & 3,35 & 3,28 & 3,30 & 3,43 & 0,05 & $-0,02$ \\
\hline 25 & 3,40 & 3,40 & 3,41 & 2,23 & $-0,01$ & $-0,01$ \\
\hline 26 & 6,05 & 5,72 & 5,66 & 5,61 & 0,39 & 0,06 \\
\hline Média & 4,12 & 4,06 & 3,98 & -- & 0,14 & 0,09 \\
\hline Desvio-padrão & 0,86 & 0,80 & 0,81 & -- & - & - \\
\hline
\end{tabular}

(1) Valores de PESN apresentados nos trabalhos de Alleoni (1992) - amostras 1 a 11 - e de Dynia (1993) - amostras 12 a 26. (2) PESN referente à média dos valores de $\mathrm{pH}$ correspondentes aos pontos de cruzamento das curvas de titulação potenciométrica tomadas duas a duas, sendo os gráficos elaborados em planilha el etrônica. (3) PESN calculado com o método analítico-computacional. (4) Coeficiente de variação associado aos valores calculados de PESN. ${ }^{(5)}$ Desvio $_{1}=$ PESN gráfico - PESN calculado. ${ }^{(6)}$ Desvio $=$ PESN gráfico $_{2}$ - PESN calculado. 
observada entre os valores calculados e os determinados manual mentefoi de 0,39 unidade de pH. Comparando os val ores calculados com os determinados em planilha el etrônica, verificou-se que a maior diferença entre eles foi de 0,22 unidade de pH.

Considerando os 26 conjuntos de dados avaliados, pôde-se notar que os valores de PESN calculados pelo programa apresentaram elevada correlação ( $r=0,99 * *)$, tanto com valores obtidos pelo método gráfico manual, quanto com aquel es obtidos a partir de gráficos gerados em planilha el etrônica.

Por outro lado, a comparação dos desvios médios referentes às diferenças entre o método analítico e os métodos gráficos, efetuada com a aplicação do teste t para amostras independentes, demonstrou quea média dos desvios observados entre os val ores de PESN calculados e os determinados pel o método gráfico manual, o qual apresenta maior subjetividade, foi significativamente maior $(p<0,05)$ que a média dos desvios observados entre os valores de PESN calculados e os obtidos a partir degráficos el aborados em planilha eletrônica.

A avaliação das análises comparativas demonstrou que o método analítico-computacional proposto mostrou-se bastante adequado para determinar o valor do PESN de amostras de solo, visto que os val ores gerados foram bastante próximos dos obtidos com o método gráfico convencional. Além disso, o sistema proporcionou rapidez e ausência de subjetividade à determinação do valor do PESN.

O programa desenvolvido, cujo aspecto geral é apresentado na figura 2, funciona em computadores IBM/PC e compatíveis e requer como configuração mínima: sistema operacional Windows 95, processador 80486, memória RAM de 16 MB, 2 MB de espaço livre no disco rígido e monitor VGA.
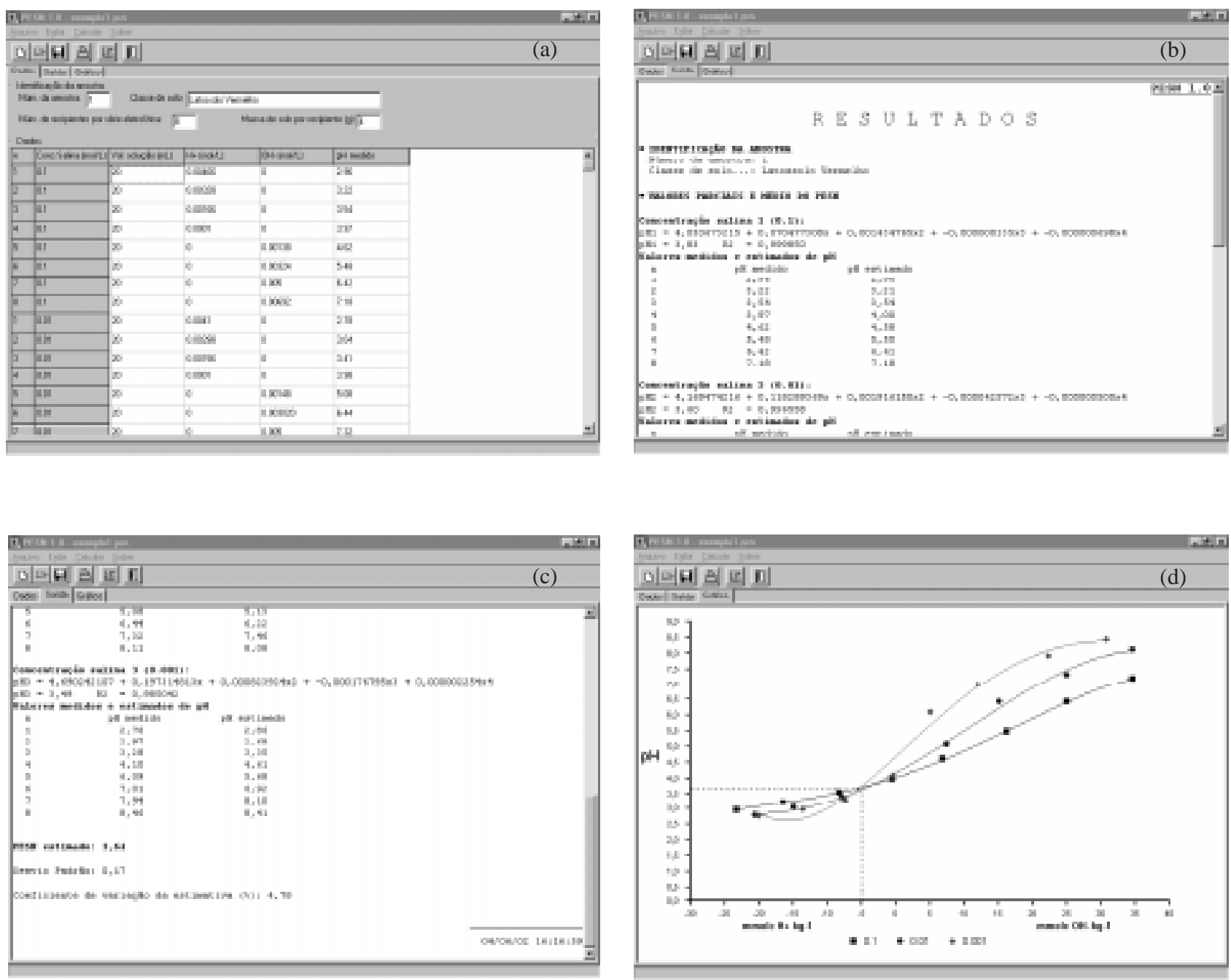

Figura 2. Aspecto geral do programa computacional para determinação analítica do PE SN com os módulos de entrada de dados (a); saída dos resultados de cálculo (b e c) e apresentação do gráfico (d). 
Os dados de entrada consistem nos seguintes itens: número da amostra, classe de solo, valores das concentrações salinas das séries eletrolíticas, massa de subamostra nos recipientes, concentrações de $\mathrm{H}^{+}$ e $\mathrm{OH}^{-}$nas soluções salinas e volume das soluções salinas nos recipientes. O programa adequa-se também à adaptação do método de titulação potenciométrica utilizado por Costa et al. (1984), no qual são adicionados pequenos volumes de ácido e base, com concentrações conhecidas, às soluções salinas contidas nos recipientes.

Além da estimativa do valor do PESN, o programa apresenta as equações de regressão ajustadas para cada série el etrolítica e seus respectivos coeficientes de determinação, os val ores medidos e estimados de $\mathrm{pH}$, os valores parciais de PESN e um gráfico, no qual são apresentados os pontos experimentais para cada concentração sal ina e as respectivas curvas de titulação potenciométrica elaboradas segundo as equações de regressão ajustadas. A apresentação gráfica dos resultados, associada ao conhecimento do coeficiente de variação da estimativa, permite avaliar melhor a precisão do valor obtido para o PESN. Além da visualização dos resultados na tela do computador, é possível a impressão dos resultados analíticos e do gráfico. A aquisição do programa pode ser efetuada gratuitamente por meio de download no endereço www.pesn.kit.net ou mediante solicitação aos autores.

\section{CONCLUSÕES}

1. O métodoanalítico-computacional desenvol vido apresentou-se adequado para a determinação rápi da e não-subjetiva do valor do PESN de amostras de solo.

2. O programa possibilitou melhor análise da precisão do valor obtido para o PESN.

\section{AGRADE CIMENTOS}

OsautoresagradecemàFAPESP, peloauxíliofinanceiro concedidopara a elaboração destetrabal ho, eaosrevisores, pelassugestões apresentadas, as quais contribuírampara a melhoriadomanuscrito.

\section{LITE RATURA CITADA}

ALLEONI, L.R.F. Atributos eletroquímicos de solos ácricos do norte paulista. Piracicaba, Escola Superior de Agricultura "Luiz de Queiroz", 1992. 121p. (Tese de Mestrado)

BUURMAN, P.; LAGEN, B. \& VELTHORST, E.J . Manual for soil and plant water analysis. Wageningen, Backhuys Publishers Leiden, 1996. 314p.

COSTA, L.M.; MORAIS, E.J .; RIBEIRO, A.C. \& FONSECA, S. Cargas elétricas de um Latossolo Vermel ho-Amarelo com diferentes coberturas florestais. R. Ceres, 31:351-359, 1984.

DYNIA, J.F. Propriedades el etroquímicas e retenção aniônica de um Latossol o Vermel ho-E scuro sob diversas práticas de manejo. Piracicaba, Escola Superior de Agricultura "Luiz de Queiroz", 1993. 122p. (Tese de Doutorado)

EMPRESA BRASILEIRA DE PESQUISA AGROPECUÁRIA EMBRAPA. Centro Nacional de Pesquisas de Solos. Manual de métodos de análise do solo. 2.ed. Rio deJ aneiro, 1997. 212p.

NETTO, A.R. I nfluência da mineralogia da fração argila sobre propriedades físico-químicas de solos brasileiros. Viçosa, UniversidadeFederal deViçosa, 1996. 144p. (Tesede Mestrado)

RAIJ , B. van \& PEECH, M. Electrochemical properties of some Oxisols and Alfisols of thetropics. Soil Sci. Soc. Am. Proc., 36:587-593, 1972.

RESENDE, M.; BAHIA FILHO, A.F.C. \& BRAGA, J.M. Mineralogia da fração argila de Latossolos estimada por alocação a partir do teor total de óxidos do ataque sulfúrico. R. Bras. Ci. Solo, 11:17-23, 1987.

SPOSITO, G. The chemistry of soils. New York, Oxford University Press, 1989. 277p. 
M. E. ALVES et al.

R. Bras. Ci. Solo, 26:553-559, 2002 